\title{
A multifaceted individualized pneumoperitoneum strategy for laparoscopic colorectal surgery: a multicenter observational feasibility study
}

\author{
Oscar Diaz-Cambronero ${ }^{1}$ Blas Flor Lorente ${ }^{2}$. Guido Mazzinari ${ }^{3} \cdot$ Maria Vila Montañes ${ }^{1}$. Nuria García Gregorio ${ }^{1}$. \\ Daniel Robles Hernandez ${ }^{4}$. Luis Enrique Olmedilla Arnal ${ }^{5}$. Maria Pilar Argente Navarro ${ }^{1}$. Marcus J. Schultz ${ }^{6,7}$. \\ Carlos L. Errando ${ }^{8}$. for the IPPColLapSe study group
}

Received: 20 March 2018 / Accepted: 18 June 2018 / Published online: 27 June 2018

(c) Springer Science+Business Media, LLC, part of Springer Nature 2018

\begin{abstract}
Background While guidelines for laparoscopic abdominal surgery advise using the lowest possible intra-abdominal pressure, commonly a standard pressure is used. We evaluated the feasibility of a predefined multifaceted individualized pneumoperitoneum strategy aiming at the lowest possible intra-abdominal pressure during laparoscopic colorectal surgery.

Methods Multicenter prospective study in patients scheduled for laparoscopic colorectal surgery. The strategy consisted of ventilation with low tidal volume, a modified lithotomy position, deep neuromuscular blockade, pre-stretching of the abdominal wall, and individualized intra-abdominal pressure titration; the effect was blindly evaluated by the surgeon. The primary endpoint was the proportion of surgical procedures completed at each individualized intra-abdominal pressure level. Secondary endpoints were the respiratory system driving pressure, and the estimated volume of insufflated $\mathrm{CO}_{2}$ gas needed to perform the surgical procedure.

Results Ninety-two patients were enrolled in the study. Fourteen cases were converted to open surgery for reasons not related to the strategy. The intervention was feasible in all patients and well-accepted by all surgeons. In 61 out of 78 patients (78\%), surgery was performed and completed at the lowest possible IAP, $8 \mathrm{mmHg}$. In 17 patients, IAP was raised up to $12 \mathrm{mmHg}$. The relationship between IAP and driving pressure was almost linear. The mean estimated intra-abdominal $\mathrm{CO}_{2}$ volume at which surgery was performed was $3.2 \mathrm{~L}$.

Conclusion A multifaceted individualized pneumoperitoneum strategy during laparoscopic colorectal surgery was feasible and resulted in an adequate working space in most patients at lower intra-abdominal pressure and lower respiratory driving pressure.

ClinicalTrials.gov (Trial Identifier: NCT03000465).
\end{abstract}

Keywords Laparoscopy $\cdot$ Colorectal surgery $\cdot$ Neuromuscular blockade

Prior presentations Preliminary data presentation at the annual congress of the European Society of Anaesthesiology (ESA) 3-5 June 2017 in Geneve-Switzerland.

Members of the IPPColLapSe study group are shown in Acknowledgements.

Electronic supplementary material The online version of this article (https://doi.org/10.1007/s00464-018-6305-y) contains supplementary material, which is available to authorized users.

Oscar Diaz-Cambronero

perioperativemedicine@iislafe.es

Extended author information available on the last page of the article
Guidelines for laparoscopic abdominal surgery recommend using the lowest possible intra-abdominal pressure (IAP) at which the surgeon has adequate workspace rather than using a standard level of IAP $[1,2]$. In clinical practice, though, IAP is typically set between 12 and $15 \mathrm{mmHg}$ throughout the entire surgical procedure [3]. Using the lowest possible IAP could be beneficial, as high IAP is associated with peritoneal damage, impaired splanchnic, hepatic and abdominal wall perfusion, decreased gastric mucosal oxygen saturation, and postoperative pain [4-8]. However, a low IAP could result in unacceptable surgical conditions, which could not only lengthen duration of surgery but also increase the risk of complications, eventually worsening outcomes $[9,10]$. 
Surgical workspace is linked to the intra-abdominal volume (IAV), the amount of insufflated $\mathrm{CO}_{2}$ gas to create the pneumoperitoneum. The IAV needed has been related to multiple but foremost modifiable factors [11]. Indeed, factors like neuromuscular blockade, pre-stretching of the abdominal wall, and patient positioning have been shown to affect the relationship between IAP and workspace [12-24]. Besides, ventilation-induced changes in intra-thoracic pressures and probably individual patient factors might impact IAP. All these factors have been studied before, but were never addressed neither investigated together.

Thus, we performed the 'Individualized PneumoPeritoneum pressure in Colorectal Laparoscopic Surgery' (IPPColLapSe) study to investigate whether a multifaceted individualized strategy, focusing on optimizing the combination of factors mentioned above during laparoscopic abdominal surgery. We were interested in its feasibility, but also the lowest IAP at which surgery could be performed using this strategy. Specifically, we assessed the proportion of patients in whom surgery was performed and completed at each individualized IAP level. We also determined the association between changes in IAP and intra-thoracic pressures, and estimated the IAV at which the laparoscopic procedure was performed. We hypothesized that a multifaceted individualized pneumoperitoneum strategy would result in lower IAP with adequate workspace for surgeons during laparoscopic colorectal surgery.

\section{Materials and methods}

\section{Design}

The IPPColLapSe study was an investigator-initiated multicenter prospective cohort investigation performed between May 2015 and October 2016 in three Spanish hospitals: The Hospital Universitario y Politécnico La Fe, Valencia, the Hospital General de Castellón, Castellon, and the Hospital Universitario Gregorio Marañon, Madrid. The study protocol was approved by the Institutional Review Boards (IRB) of all three hospitals (protocol number: 2015/0094). The trial was registered with ClinicalTrials.gov (Trial Identifier: NCT03000465). Written informed consent was obtained from all participants before surgery.

\section{Population}

Patients were eligible for participation if (a) scheduled for laparoscopic colorectal surgery; (b) age > 18-year-old; and (c) American Society of Anesthesiologists (ASA) physical status I to III, with no cognitive deficits. Exclusion criteria included the following: (a) emergency or unplanned surgery; (b) impossibility to obtain written informed consent; and (c) allergy to, or contraindication for rocuronium or sugammadex. Women who were pregnant or breastfeeding, patients with known immunologic or neuromuscular diseases, and patients with an advanced stage of cardiopulmonary, renal, or hepatic diseases were excluded from participation.

\section{Standard procedures}

After initiation of standard monitoring and continuous neuromuscular monitoring (TOF-Watch-SXTM, OrganonTeknika, Oss, The Netherlands), anesthesia was induced using propofol (1.5 to $\left.2 \mathrm{mg} \mathrm{kg}^{-1}\right)$ plus fentanyl $\left(1 \mu \mathrm{g} \mathrm{kg}^{-1}\right)$. Tracheal intubation was facilitated with rocuronium 0.6 $\mathrm{mg} \mathrm{kg}^{-1}$. Anesthesia was maintained using propofol infusion titrated to a bispectral index (BIS, BIS ${ }^{\mathrm{TM}}$, Covidien, Mansfield, MA, USA) between 40 and 60. Additional fentanyl boluses $\left(1 \mu \mathrm{g} \mathrm{kg}^{-1}\right)$ were used for intraoperative analgesia. An electronic $\mathrm{CO}_{2}$ gas insufflator (Endoflator ${ }^{\mathrm{TM}}$, Karl Storz, Tuttlingen, Germany) was used for $\mathrm{CO}_{2}$ insufflation into the abdominal cavity through a paraumbilical-placed laparoscopic trocar.

\section{Intervention}

The following predefined interventions, as part of the multifaceted individualized pneumoperitoneum strategy, were performed in all patients, in the same order:

1. Tidal volume reduction with volume controlled ventilation mode to $8 \mathrm{ml} \mathrm{kg}^{-1}$ of predicted ideal body weight (PBW), 20\% inspiratory pause, positive end-expiratory pressure (PEEP) set at 5 or $10 \mathrm{~mm} \mathrm{Hg}$, in patients with a body mass index $(\mathrm{BMI})<30$ or $>30 \mathrm{~kg} \mathrm{~m}^{-2}$, respectively, oxygen inspiratory fraction 0.8 and respiratory rate 12 to 15 respirations per minute to maintain standard end-tidal $\mathrm{CO}_{2}$ values [25].

2. A 'modified lithotomy position' with slightly flexed hips $\left(45-90^{\circ}\right)$ respect to patients' legs raised in padded supports. This increases the anteroposterior intra-abdominal space by correcting lumbar lordosis;

3. Continuous deep neuromuscular blockade throughout surgery to maintain a train-of-four (TOF) of 0 and posttetanic count (PTC) between 1 and 5;

4. Pre-stretching of the abdominal wall muscles, setting pneumoperitoneum at $15 \mathrm{mmHg}$ for a maximum of 5 min during initial $\mathrm{CO}_{2}$ gas insufflation and trocars insertion; (insufflator initially set at $15 \mathrm{mmHg}$ with an initial flow rate of $31 \mathrm{~min}^{-1}$ );

5. Individualized IAP titration. After pre-stretching, the patient was placed in the $20^{\circ}$ Trendelemburg position. Flow rate was set at $301 \mathrm{~min}^{-1}$ and the surgery began. The IAP was initially decreased from 15 to $12 \mathrm{mmHg}$, and then stepwise to $11,10,9$, and finally $8 \mathrm{mmHg}$. IAP 
was allowed to stabilization after each step, lasting usually 3 to $5 \mathrm{~min}$. Surgeons were blinded to the actual IAP used, and could request at any time to increase IAP, if workspace became 'non-adequate.' If deemed necessary, this increment was done in $1 \mathrm{mmHg}$ steps lasting at least $1 \mathrm{~min}$, up to the level at which the surgical workspace became adequate with an upper limit of $15 \mathrm{~mm} \mathrm{Hg}$. While it is common that the surgeon decides on the level of IAP to be used, here an anesthesiologist managed the pneumoperitoneum insufflator and surgeons remained blinded to the level of IAP used.

\section{Data collected}

Data on weight, sex, height, age, gender, body mass index (BMI), number of pregnancies, number of previous laparoscopic surgeries, and type and duration of surgery were collected. IAP was measured at every liter during pneumoperitoneum insufflation until $15 \mathrm{mmHg}$ level was reached. We also measured the IAV of $\mathrm{CO}_{2}$ gas insufflated at $15 \mathrm{mmHg}$. Ventilation parameters were collected at each down titration step of IAP. Parameters recorded included PEEP, peak pressure (Ppeak) and plateau pressure (Pplat), and respiratory system compliance $\left(\mathrm{C}_{\mathrm{RS}}\right)$.

\section{Definitions}

The 'individualized IAP' was defined as the highest IAP needed to obtain and maintain an adequate workspace until completion of surgery. 'Adequate workspace' was defined as the workspace sufficient to perform the surgical procedure with no need for corrective measures (IAP increment) as judged by the operating surgeon. Consequently, 'non-adequate workspace' was defined as workspace insufficient to perform the surgical procedure with the need for corrective measures. Surgeons were kept blinded to the actual level of IAP used at any time during the surgical procedure, but were advised if the level was over the predefined upper limit.

The 'respiratory system driving pressure' $\left(\Delta \mathrm{P}_{\mathrm{RS}}\right)$ was calculated by subtracting PEEP from Pplat. The optimized IAV was defined as the 'volume of insufflated $\mathrm{CO}_{2}$ at the individualized IAP' and was estimated from the IAP/IAV curve for each patient during insufflation.

\section{Endpoints}

The primary endpoint was the proportion of patients at each level of individualized IAP. Secondary endpoints were ventilation parameters evaluation during the stepwise IAP deflation, including Ppeak, Pplat and PEEP, and the $\Delta \mathrm{P}_{\mathrm{RS}}$, and IAV estimation at the individualized IAP.

\section{Sample size calculation}

Assuming that surgery can be performed with a mean IAP of $9 \mathrm{mmHg}$ with standard deviation (SD) of 1.9 (pilot unpublished study, laparoscopic colorectal surgery), 78 patients would be included to assess the individualized IAP with $95 \%$ confidence and achieving an accuracy of \pm 0.5 in the determination of the 50th percentile, \pm 0.55 in the 25th and 75th percentiles and of \pm 0.65 in the 10th and 90 th percentiles.

If conversion to open surgery was decided, the patient was excluded from the analysis of the primary outcome, and replaced with a new patient until 78 patients were enrolled and completed the study concerning the primary endpoint. Patients in whom surgeons decided to convert to open surgery remained analyzable for the other endpoints.

\section{Analysis plan and statistical analyses}

Data were expressed as mean (SD) or median [IQR] for continuous variables and by counts and proportions for categorical variables with. The $95 \%$ confidence intervals were calculated for each of the estimated percentiles.

The proportion of patients in whom surgery was finished at each IAP level was first analyzed. Next, the relationship between IAP and ventilation parameters, in particular, $\Delta \mathrm{P}_{\mathrm{RS}}$ was calculated. For this calculation, a quantile regression model with splines for the median and 10th and 90th percentiles, adding BMI and age as covariates, was adjusted.

The relationship between IAP and the insufflated volume of $\mathrm{CO}_{2}$ was determined for each patient during initial pneumoperitoneum insufflation until an IAP of $15 \mathrm{mmHg}$ was reached. The optimized IAV was estimated from data in patients in whom surgery was finished by laparoscopy. The relationship between IAP and IAV was analyzed by linear interpolation from the individual IAP/IAV curves. The IAP before $\mathrm{CO}_{2}$ gas insufflation was considered the basal IAP or intra-abdominal pressure at volume zero, and was estimated by fitting multiadaptive linear regression splines to intraabdominal volume and pressure relationship.

We performed a posthoc analysis fitting a linear mixed model with surgeon as random effect to determine factors that influenced the optimized IAV. The factors tested in the model included: Age, gender, BMI, pregnancies, previous laparoscopic or open surgeries, type of surgery (right or left hemicolectomy, rectum or other surgeries), IAV at $15 \mathrm{mmHg}$ of IAP, and intra-abdominal pressure at volume zero (Pv0) were included.

Statistical analyses were performed with R statistical software version 3.3.3 (R Foundation for Statistical Computing, Vienna, Austria). 


\section{Results}

\section{Patients}

Ninety-two patients were finally enrolled. Fourteen procedures were converted to open surgery (Fig. 1). In all cases, the surgeons confirmed that the decision to conversion was not related to the IPP. All other 78 patients could be followed to the primary endpoint of the study. Baseline

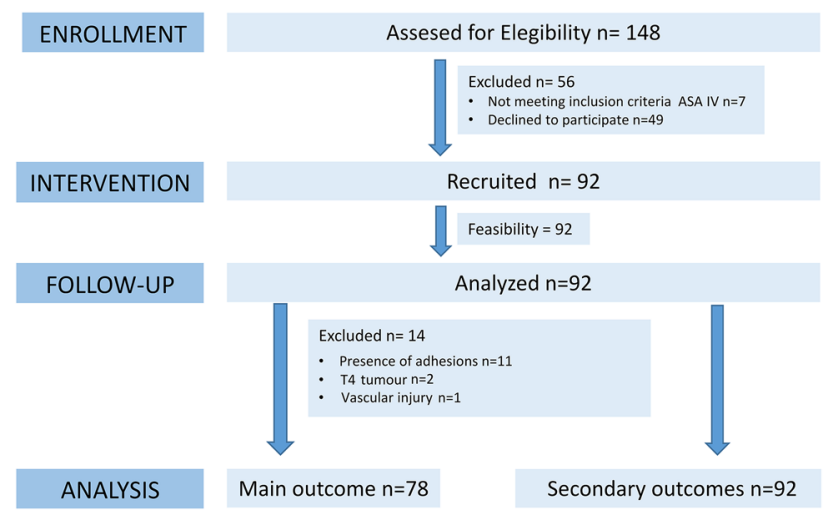

characteristics are presented in Table 1. Surgeons experience is detailed in eTable1.

\section{Feasibility}

The multifaceted and individualized strategy was feasible in all 92 enrolled patients, resulting in adequate workspace for the surgeon in all cases. Seventy-eight patients fulfill criteria to be analyzed for the primary endpoint. In 61 patients (78\% [95\% CI 70-89\%]), the lowest IAP was $8 \mathrm{mmHg}$ until the end of surgery. In the remainder 17 patients, uptitration was necessary during surgery, up to IAPs between 9 and $12 \mathrm{mmHg}$ (Fig. 2).

The median optimized IAV of insufflated $\mathrm{CO}_{2}$ was 3.2 [2.7-4.2] liters, or 58 [49-67] $\mathrm{ml} \mathrm{kg}^{-1}$ body weight (eFigure 1 and eFigure 2).

\section{Relationship between IAP and $\Delta \mathrm{P}_{\mathrm{RS}}$}

The relationship between IAP and $\Delta \mathrm{P}_{\mathrm{RS}}$ was almost linear (Fig. 3 and eTable 2), every reduction in IAP of $1 \mathrm{mmHg}$ resulted in a reduction in $\Delta \mathrm{P}_{\mathrm{RS}}$ of $0.74 \mathrm{cmH}_{2} \mathrm{O}$ (or $0.56 \mathrm{~mm} \mathrm{Hg}$ ) between 8 and $15 \mathrm{mmHg}$.

Fig. 1 IPPColLapSe Flowchart

Table 1 Patients' characteristics

All outcomes analyzed $(n=78) \quad \begin{aligned} & \text { Only Secondary outcome } \\ & \text { analyzed }(n=14)\end{aligned} \quad$ All patients $(n=92)$

\begin{tabular}{|c|c|c|c|}
\hline Age (year) & $64.1(13.2)$ & $68.7(11.5)$ & $64.8(13.0)$ \\
\hline Gender (male/female) & $45 / 33(58 / 42)$ & $9 / 5(64 / 36)$ & $54 / 38(59 / 41)$ \\
\hline $\operatorname{BMI}\left(\mathrm{Kg} \mathrm{m}^{-2}\right)$ & $26.4(4.0)$ & $28.6(4.5)$ & $26.7(4.2)$ \\
\hline Surgery time (minutes) & $232(89)$ & $284(79)$ & $240(89)$ \\
\hline Hospital Marañón/La Fe/Castellón & $5 / 49 / 24(6 / 63 / 31)$ & $0 / 11 / 3(0 / 79 / 21)$ & $5 / 60 / 27(5 / 65 / 30)$ \\
\hline ASA I/II/III & $10 / 54 / 14(13 / 69 / 18)$ & $1 / 10 / 3(7 / 71 / 21)$ & $11 / 64 / 17(12 / 70 / 18)$ \\
\hline Previous laparoscopic surgery $0 / 1 / 2 / 3 / 4$ & $64 / 12 / 1 / 1(82 / 16 / 1 / 1)$ & 10/3/0/1 (72/21/7) & 73/14/1/1/1 (81/16/1/1) \\
\hline Previous pregnancies $0 / 1 / 2 / 3 / 4 / 5 / 6$ & $58 / 7 / 5 / 5 / 1 / 1 / 1(74 / 9 / 7 / 7 / 1 / 1 / 1)$ & $9 / 1 / 3 / 1 / 0 / 0 / 0(64 / 7 / 21 / 8 / 0 / 0)$ & $67 / 8 / 8 / 6 / 1 / 1 / 1(73 / 9 / 9 / 6 / 1 / 1 / 1)$ \\
\hline \multicolumn{4}{|l|}{ Scheduled surgery $(n=77)$} \\
\hline Right hemicolectomy & $40(52)$ & $8(57)$ & $48(53)$ \\
\hline Left hemicolectomy & $9(12)$ & $2(14)$ & $11(12)$ \\
\hline Sigmoidectomy & $15(18)$ & $3(21)$ & $17(19)$ \\
\hline Rectum anterior resection & $9(12)$ & $0(0)$ & $9(10)$ \\
\hline Total colectomy & $2(3)$ & $1(7)$ & $3(3)$ \\
\hline Ileocecal resection & $2(3)$ & $0(0)$ & $2(2)$ \\
\hline Terminal colostomy & $1(1)$ & $0(0)$ & $1(1)$ \\
\hline Oncologic surgery (yes/No) & $\begin{array}{l}68 / 10 \\
(87 / 13)\end{array}$ & $\begin{array}{l}14 / 0 \\
(100 / 0)\end{array}$ & $\begin{array}{l}82 / 10 \\
(89 / 11)\end{array}$ \\
\hline Hospital length of stay (days) & $6[5-8]$ & $6[6-8]$ & $6[5-8]$ \\
\hline
\end{tabular}

Data as mean (SD), number (\%) or median [25th-75th percentile]

$B M I$ Body mass index, ASA American Society of Anesthesiologists physical status 


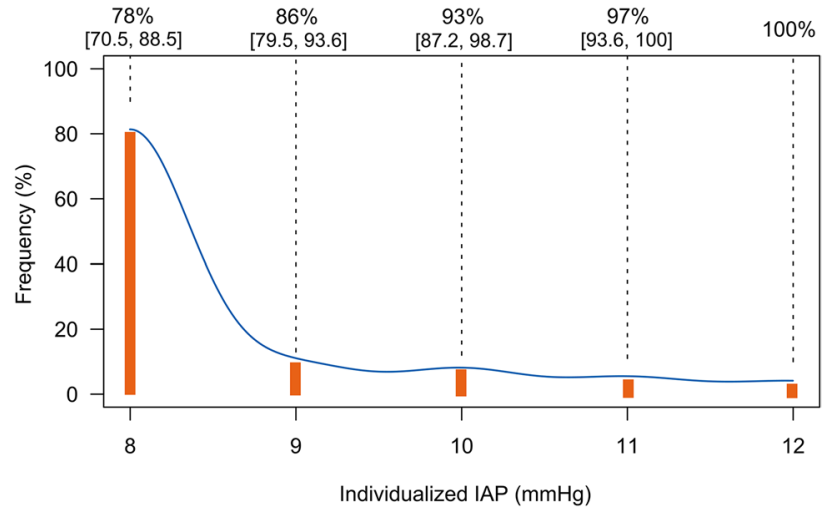

Fig. 2 Proportion of surgical procedures finished at each IAP level; IAP in $\mathrm{mmHg}$. Solid blue line: estimated probability density function distribution in the population for IAP. Orange columns: patients' relative frequency. Upper row: cumulative frequency and 95\% CI. Data are reported for the 78 patients analyzed for primary outcome

\section{Relationship between IAP and volume of insufflated $\mathrm{CO}_{2}$ gas}

A nonlinear relationship between IAP and volume of insufflated gas was found (Fig. 4). A breakpoint in the IAP/IAV at $10 \mathrm{mmHg}$ (mean) was observed between 8 and $15 \mathrm{~mm} \mathrm{Hg}$ IAP.

\section{Posthoc analysis}

Mainly, the volume of $\mathrm{CO}_{2}$ insufflated at $15 \mathrm{~mm} \mathrm{Hg}$ of IAP during pneumoperitoneum generation and $\mathrm{Pv} 0$ were associated with the optimized IAV (eTable 3).

\section{Discussion}

The findings of this study in patients undergoing laparoscopic colorectal surgery can be summarized as follows: (a) the tested multifaceted individualized strategy was feasible; (b) resulted in an adequate workspace throughout surgery, and (c) allows to use lower IAP than frequently selected for pneumoperitoneum in most patients. Moreover, lowering IAP resulted in (d) a substantial decrease of $\Delta \mathrm{P}_{\mathrm{RS}}$; and (e) an optimized IAV close to 3 liters. Finally, (f) a decrease in abdominal compliance was identified at a mean IAP of $10 \mathrm{~mm} \mathrm{Hg}$.

This study tested the feasibility of a multifaceted and individualized intervention focusing on IAP in colorectal laparoscopic surgery. The multidisciplinary teamwork with close collaboration between surgeons and anesthesiologist allowed us to develop and perform this study. Over ten surgeons participated in this study, external validity of results was warranted provided the range of surgeons' experience in colorectal laparoscopic surgery. There have been no prior studies in which the relation between IAP and IAV was determined for each individual patient.
Fig. 3 The relationship between (IAP) and respiratory driving pressure $\left(\Delta \mathrm{P}_{\mathrm{RS}}\right)$. IAP in $\mathrm{mmHg}$ and $\Delta \mathrm{P}_{\mathrm{RS}}$ in $\mathrm{cmH}_{2} \mathrm{O}$. Upper line 90th percentile; Lower line, 10th percentile; Middle line 50 th percentile. Blue is $95 \%$ confidence bandwidth for 50th percentile. Data are reported for the 92 patients analyzed for all outcomes. (Color figure online)

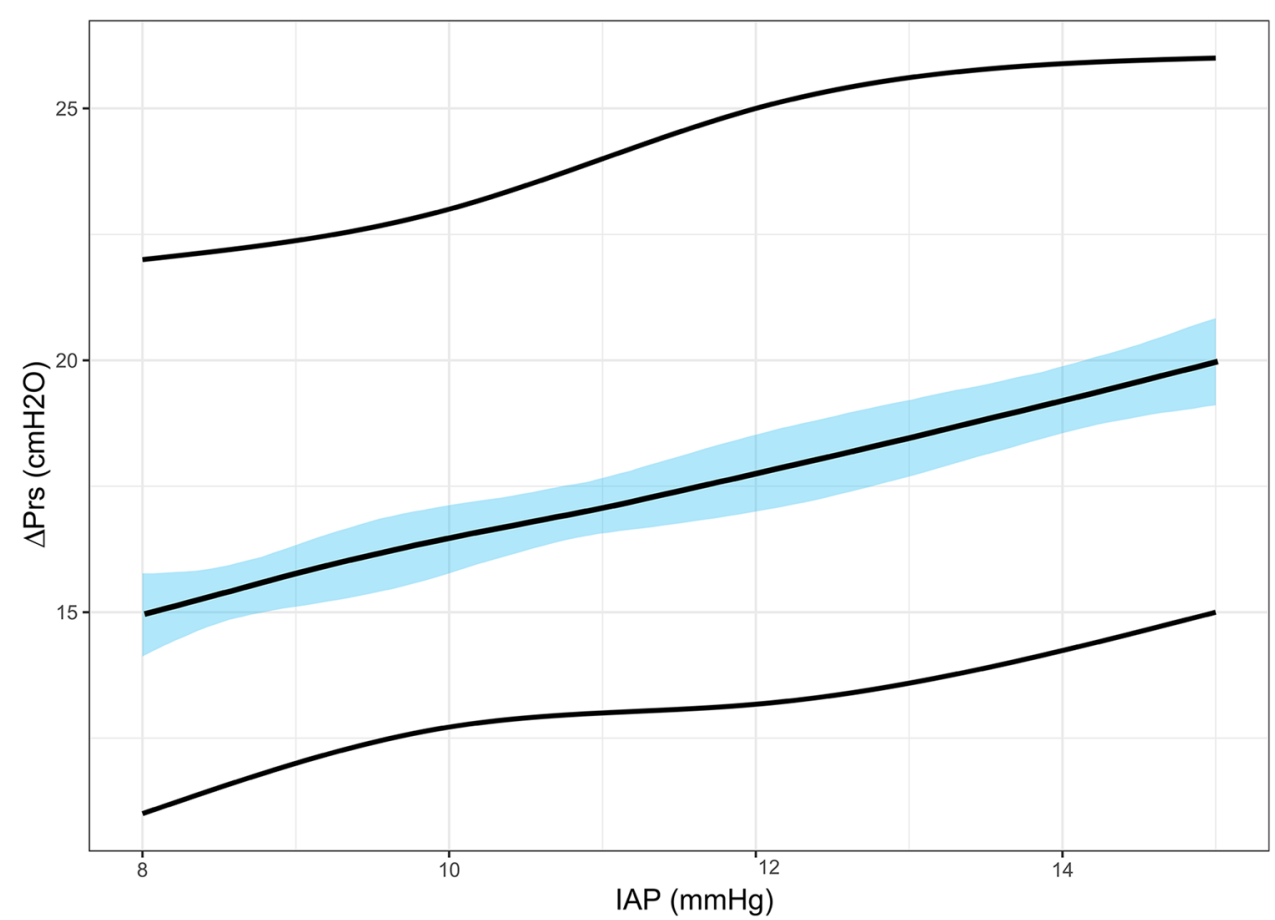


Fig. 4 The relationship between IAV and IAP; IAP in mmHg, IAV in liters; Grey points: individual patient data. Data are reported for the 92 patients analyzed for all outcomes

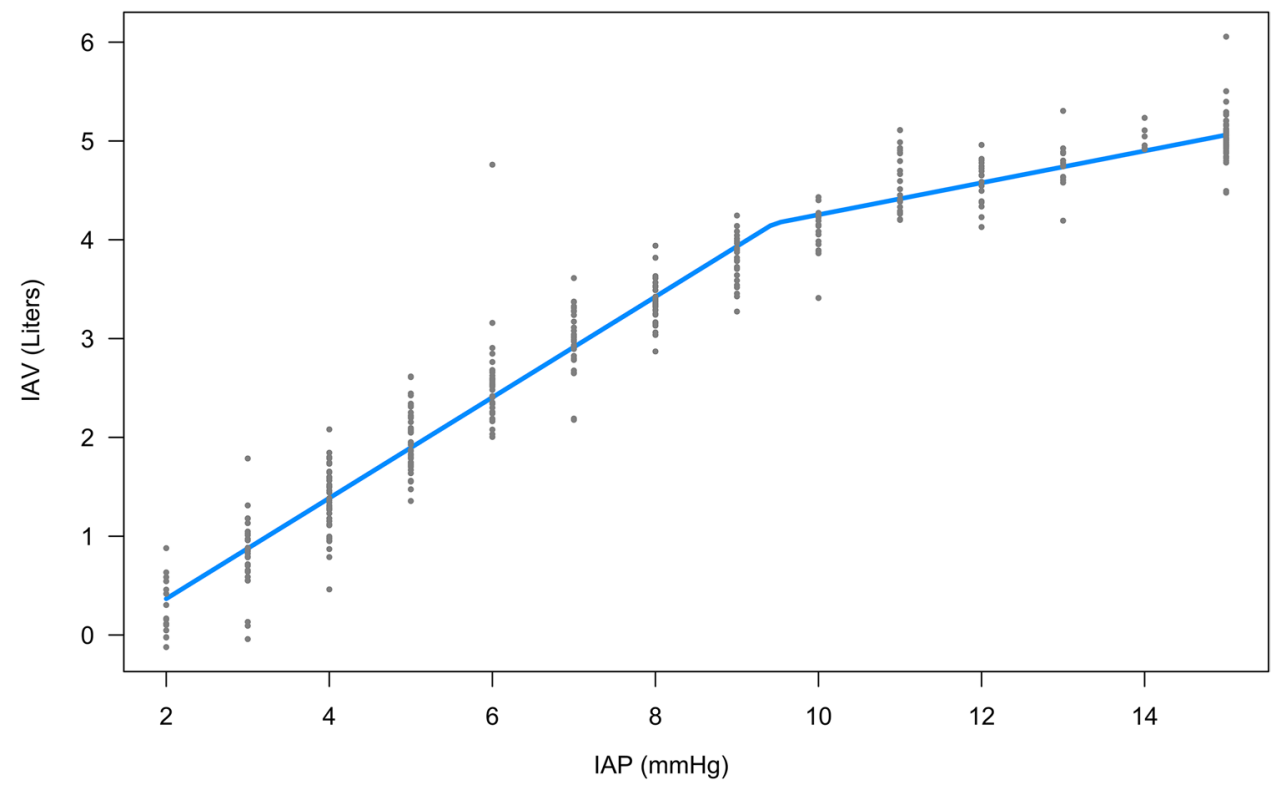

Since we tested a multifaceted strategy, with five different elements, it remains uncertain what exactly allowed us to reduce IAP, i.e., which one factor had the biggest impact. Previous studies tested the individual elements, but there were no investigations that combined all five items into one bundle.

The impact of ventilator settings on IAP, and vice versa has been extensively studied in the critical care setting, but not in laparoscopic abdominal surgery, in the tested strategy we deliberately choose using low tidal volume to decrease the impact on IAV [25]. One study in 20 patients under bariatric laparoscopic surgery showed that, in supine position, raising the legs to a modified lithotomy position increased the IAV generated during pneumoperitoneum, the effect being more important in Trendelenburg position [26]. Deep neuromuscular blockade throughout the surgical procedure has been compared with moderate or no blockade, studies offering inconclusive results, or marginal gains [12-16]. Seven randomized clinical trials comparing deep versus moderate neuromuscular blockade showed positive effects on surgical conditions during retroperitoneal laparoscopic procedures [17], laparoscopic donor nephrectomy [18], and laparoscopic hysterectomy [19], and a marginally positive effect in laparoscopic cholecystectomy [20-24]. In laparoscopic cholecystectomies, the percentage of procedures finished at low IAP was $60 \%$ with deep neuromuscular blockade versus $35 \%$ with moderate neuromuscular blockade [20]. On the other hand, pre-stretching of the abdominal wall muscles has only been evaluated in animal studies, showing an increase in IAV, when insufflated at $15 \mathrm{mmHg}$, with a more important effect at lower IAP [27]. Finally, individually IAP titration has been studied in two investigations at different levels of neuromuscular blockade. In a prospective observational study in 20 patients undergoing laparoscopic cholecystectomy, deep versus no neuromuscular blockade allowed a decrease in mean IAP of $6 \mathrm{~mm} \mathrm{Hg}$ (starting with $13 \mathrm{mmHg}$ ), but a further increase in $3 \mathrm{~mm} \mathrm{Hg}$ after $15 \mathrm{~min}$ was necessary [28]. In a clinical trial including 61 patients undergoing colorectal laparoscopic surgery, moderate neuromuscular blockade was compared with deep neuromuscular blockade. Deep neuromuscular blockade resulted in a lower mean IAP (9 mm Hg) [29]. In our study, we combined all measures into a multifaceted individualized IAP strategy, resulting in lower levels of IAP.

In recent studies, $\Delta \mathrm{P}_{\mathrm{RS}}$ has been shown to be independently associated with the development of postoperative pulmonary complications (PPC) in surgical patients [30]. It is known that pneumoperitoneum insufflation decreases chest wall compliance, impairing respiratory function [31, 32]. Studies in animal models have further shown a 40 to $50 \%$ transmission of IAP to the intra-thoracic one, and thus on ventilation pressures $[33,34]$. Of note, there have been no studies in humans yet, and the impact of IAP on $\Delta \mathrm{P}_{\mathrm{RS}}$ in the laparoscopic surgery setting remains to be explored, we tested the impact of our strategy on the resulting relationship between IAP and $\Delta \mathrm{P}_{\mathrm{RS}}$. The results suggest a transmission rate of $56 \%$ at clinically relevant pressure ranges for laparoscopy (i.e., $8-15 \mathrm{mmHg}$ ). Although the design of a comprehensive protective ventilation strategy is beyond the scope of the present investigation, its results suggest that an individualized multifaceted strategy aimed at lowering IAP during laparoscopy could benefit patients through a lower $\Delta \mathrm{P}_{\mathrm{RS}}$.

The relationship between IAP and IAV is often considered to be linear during laparoscopic surgery in the 12 to $15 \mathrm{mmHg}$ range $[35,36]$. However, we observed a 
'breakpoint' at IAP of $10 \mathrm{~mm} \mathrm{Hg}$. It would be interesting to identify it to avoid IAP increases that correlate with minor or no IAV increases at all, i.e., no clinical benefit.

The present study reported the precise IAV needed to perform lower abdominal laparoscopic surgery. Our results are in line with results reported for upper abdominal bariatric laparoscopic surgery. Indeed, an IAV of 31 seems to be the threshold for optimal surgical conditions [26]. Being aware of the optimized IAV allows a goal directed initial insufflation of $\mathrm{CO}_{2}$. Future $\mathrm{CO}_{2}$ insufflators may include automatic and real-time determination of the relationship between IAP and IAV to allow better individualization of IAP throughout the entire surgical procedure.

This study has several limitations. Although the surgeons confirmed that the reasons for conversion to open surgery were independent from the tested intervention, we cannot be certain this was really the case. Of note, in none of these patients, was there a request to increase the IAP. A conversion rate of $\sim 15 \%$ is commonplace for this type of surgery [37]. We tested a bundle of measures, some of them could be standard of care, and, as mentioned above, it remains uncertain which of those factors had the biggest impact on IAP. Surgeons were blinded for the IAP but not for the patient's inclusion in the study. As dictated by the study protocol, IAP downtitration stopped at $8 \mathrm{mmHg}$ while in some patients a lower IAP could still have resulted in acceptable workspace for the surgeon. Again, in the patients with highest intra-abdominal volume during pneumoperitoneum insufflation, the optimized calculated Intra-abdominal volume at individualized IAP was probably higher than needed. In this real-life study with several study centers and several surgeons involved, there is a possibility of significant variability in the surgeon's comfort level with respect to available workspace, (efigure 1 and efigure2). Blinded surgeons evaluate surgical conditions in a practical dichotomous manner as adequate or not depending on whether they needed any corrective action. This makes comparison with other studies as those using the Leiden-Surgical Rating Scale, difficult [17, 18]. We did not use oesophageal catheters to estimate intrapleural pressures. The transpulmonary pressure $\Delta \mathrm{P}$, calculated from intrapleural pressures, could be more informative than the $\Delta \mathrm{P}_{\mathrm{RS}}$. Besides, clinical outcomes after surgery were not evaluated.

As conclusion, a multifaceted individualized pneumoperitoneum strategy was feasible and resulted in an adequate workspace for surgeons at lower IAP than usually applied during laparoscopic colorectal surgery. Furthermore, through intra-abdominal pressure optimization, lower respiratory driving pressure was achieved. Benefits of the tested intervention on patient recovery and perioperative morbidity must be tested in randomized controlled trials.
Acknowledgements We acknowledge the support of surgery, anesthesia, and administrative staff at the Hospital Universitario y Politecnico $\mathrm{La} \mathrm{Fe}$ in Valencia, the Hospital General de Castellon in Castellon, and the Hospital Universitario Gregorio Marañon in Madrid, Spain, during this study and a special mention to David Hervás from Data Science and Biostatistics IISLaFe for the assistance with the data analysis.

IPPColLapSe study collaborators group members: Salvador Pous Ph.D. (salvadorpous@ hotmail.com), Cristina Ballester Ph.D. (cris7balle@yahoo.es), Matteo Frasson Ph.D. (dr.frasson.matteo@gmail. com), Alvaro García-Granero Ph.D. (alvarogggt@hotmail.com), Carlos Cerdán Santacruz M.D. (carloscerdansantacruz@hotmail. com), Eduardo García-Granero Ph.D. (eggranero@telefonica.net), Luis Sanchez Guillen M.D. (drsanchezguillen@gmail.com), Anabel Marqués Marí Ph.D. (amarquesmari@gmail.com), David Casado Rodrigo M.D. (dcasador@ hotmail.com), Joan Gibert Gerez M.D. (jgibertgerez@me.com), Rebeca Cosa Rodríguez M.D. (rebecacosa@ hotmail.com), $\mathrm{M}^{\mathrm{a}}$ de los Desamparados Moya Sanz M.D. (desampa. moya@gmail.com), Marcos Rodriguez Martín M.D. (marcosrodmar@ hotmail.com), Jaime Zorrilla Ortúzar M.D. (jzorrillaortuzar@gmail. com), José María Pérez-Peña M.D. (jppena@salud.madrid.org), Maria Jose Alberola Estellés M.D. (majoni2000@yahoo.es), Begoña Ayas Montero Ph.D. (bego_ayas@ hotmail.com), Salome Matoses Jaen M.D. (smatosesj@gmail.com), Sandra Verdeguer Ph.D. (sandraverdeguer@ hotmail.com), Michiel. Warlé M.D. (Michiel.Warle@ radboudumc.nl), David Cuesta Frau Ph.D. (dcuesta@ disca.upv.es.)

Author contributions O.D.C: Study design, acquisition, analysis and interpretation of data, drafting and revision of paper. B.F.L: Study design, acquisition, analysis and interpretation of data, drafting and revision of paper. G.M: Study design, analysis and interpretation of data, drafting and revision of paper. M.V.M: Study design, acquisition and interpretation of data, and revision of paper. N.G.G: Study design, acquisition and interpretation of data, and revision of paper. D.R.H: Study design, acquisition and interpretation of data, and revision of paper. L.E.O.A: Study design, acquisition and interpretation of data, and revision of paper. M.P.A.N: Study design, interpretation of data, and revision of paper. M.J.S: Analysis and interpretation of data, drafting and revision of paper. C.L.E.O: Study design, analysis and interpretation of data, drafting and revision of paper.

Funding Support was provided solely from institutional and/or departmental sources.

\section{Compliance with Ethical Standards}

Disclosures Oscar Diaz-Cambronero (oscardiazcambronero@gmail. com) has received speakers' fees and honoraria from Merck Sharp \& Dohme for lectures (approximately amount: 8.000 euros) and also received a research grant from Merck Sharp \& Dohme of 80.000 euros not related to this study. Blas Flor Lorente (blasflor@hotmail.com) has received speakers' fees and honoraria from Merck Sharp \& Dohme for lectures (approximately amount: 3.000 euros). Guido Mazzinari (gmazzinari@gmail.com) declares no competing interests. Maria Vila Montañes (mvilamontanes@yahoo.es) declares no competing interests. Nuria Garcia Gregorio (nuriagcia6@ gmail.com) declares no competing interests. Daniel Robles Hernandez (drobher@gmail.com) declares no competing interests. Luis Enrique Olmedilla Arnal (lolmedilla@ gmail. com) declares no competing interests. Maria Pilar Argente Navarro (argente_marnav@gva.es) has received speakers' fees and honoraria for lectures from Merck Sharp \& Dohme (approximately amount: 1.000 euros). Marcus J. Schultz (marcus.j.schultz@gmail.com) declares no competing interests. Carlos L. Errando (errando013@gmail.com) has received speakers' fees and honoraria for lectures from Merck Sharp \& Dohme. (approximately amount: 1.000 euros). 


\section{References}

1. Neudecker J, Sauerland S, Neugebauer E, Bergamaschi R, Bonjer HJ, Cuschieri A, Fuchs KH, Jacobi Ch, Jansen FW, Koivusalo AM, Lacy A, McMahon MJ, Millat B, Schwenk W (2002) The European Association for Endoscopic Surgery clinical practice guideline on the pneumoperitoneum for laparoscopic surgery. Surg Endosc 16:1121-1143

2. Hatipoglu S, Akbulut S, Hatipoglu F, Abdullayev R (2014) Effect of laparoscopic abdominal surgery on splanchnic circulation: Historical developments. World J Gastroenterol 20:18165-18176

3. Gurusamy KS, Vaughan J, Davidson BR (2014) Low pressure versus standard pressure pneumoperitoneum in laparoscopic cholecystectomy. Cochrane Database of Syst Rev 3:CD006930

4. Brokelman WJ, Lensvelt M, Borel Rinkes IH, Klinkenbijl JH, Reijnen MM (2011) Peritoneal changes due to laparoscopic surgery. Surg Endosc 25:1-9

5. Maddison L, Karjagin J, Tenhunen J, Starkopf J (2012) Moderate intra-abdominal hypertension is associated with an increased lactate-pyruvate ratio in the rectus abdominis muscle tissue: a pilot study during laparoscopic surgery. Ann Intensive Care 2(Suppl 1):S14

6. Malbrain ML, Viaene D, Kortgen A, De Laet I, Dits H, Van Regenmortel N, Schoonheydt K, Bauer M (2012) Relationship between intra-abdominal pressure and indocyanine green plasma disappearance rate: hepatic perfusion may be impaired in critically ill patients with intra-abdominal hypertension. Ann Intensive Care 2(Suppl 1):S19

7. Papparella A, Nino F, Coppola S, Noviello C, Paciello O, Papparella S (2013) Peritoneal morphological changes due to pneumoperitoneum: the effect of intra-abdominal pressure. Eur J Pediatr Surg 24:322-327

8. Schwarte LA, Scheeren TW, Lorenz C, De Bruyne F, Fournell A (2004) Moderate increase in intraabdominal pressure attenuates gastric mucosal oxygen saturation in patients undergoing laparoscopy. Anesthesiology 100:1081-1087

9. Procter LD, Davenport DL, Bernard AC, Zwischenberger JB (2010) General surgical operative duration is associated with increased risk-adjusted infectious complication rates and length of hospital stay. J Am Coll Surg 210:60-65

10. Cheng H, Chen BP, Soleas IM, Ferko NC, Cameron CG, Hinoul $P$ (2017) Prolonged operative duration increases risk of surgical site infections: a systematic review. Surg Infect 18:722-735

11. Vlot J, Wijnen R, Stolker RJ, Bax K (2013) Optimizing working space in porcine laparoscopy: CT measurement of the effects of intra-abdominal pressure. Surg Endosc 27:1668-1673

12. Madsen MV, Staehr-Rye AK, Gätke MR, Claudius C (2015) Neuromuscular blockade for optimising surgical conditions during abdominal and gynaecological surgery: a systematic review. Acta Anaesthesiol Scand 59:1-16

13. Madsen MV, Staehr-Rye AK, Claudius C, Gätke MR (2016) Is deep neuromuscular blockade beneficial in laparoscopic surgery? Yes, probably. Acta Anaesthesiol Scand 60:710-716

14. Kopman AF, Naguib M (2015) Laparoscopic surgery and muscle relaxants. Anesth Analg 120:51-58

15. Kopman AF, Naguib M (2016) Is deep neuromuscular block beneficial in laparoscopic surgery? No, probably not. Acta Anaesthesiol Scand 60:717-722

16. Bruintjes MH, van Helden EV, Braat AE, Dahan A, Scheffer GJ, van Laarhoven CJ, Warlé MC (2017) Deep neuromuscular block to optimize surgical space conditions during laparoscopic surgery: a systematic review and meta-analysis. Br J Anaesth 118:834-842

17. Martini CH, Boon M, Bevers RF, Aarts LP, Dahan A (2014) Evaluation of surgical conditions during laparoscopic surgery in patients with moderate vs deep neuromuscular block. Br J Anaesth 112:498-505

18. Özdemir-van Brunschot DMD, Braat AE, van der Jagt MFP, Scheffer GJ, Martini CH, Langenhuijsen JF, Dam RE, Huurman VA, Lam D, d'Ancona FC, Dahan A, Warle MC (2018) Deep neuromuscular blockade improves surgical conditions during lowpressure pneumoperitoneum laparoscopic donor nephrectomy. Surg Endosc 32:245-251

19. Dubois PE, Putz L, Jamart J, Marotta ML, Gourdin M, Donnez O (2014) Deep neuromuscular block improves surgical conditions during laparoscopic hysterectomy: a randomised controlled trial. Eur J Anaesthesiol 31:430-436

20. Staehr-Rye AK, Rasmussen LS, Rosenberg J, Juul P, Lindekaer AL, Riber C, Gätke MR (2014) Surgical space conditions during low-pressure laparoscopic cholecystectomy with deep versus moderate neuromuscular blockade: a randomized clinical study. Anesth Analg 119:1084-1092

21. Madsen MV, Gätke MR, Springborg HH, Rosenberg J, Lund J, Istre O (2015) Optimising abdominal space with deep neuromuscular blockade in gynaecologic laparoscopy - a randomised, blinded crossover study. Acta Anaesthesiol Scand 59:441-447

22. Barrio J, Errando CL, San Miguel G, Salas BI, Raga J, Carrión JL, García-Ramón J, Gallego J (2016) Effect of depth of neuromuscular blockade on the abdominal space during pneumoperitoneum establishment in laparoscopic surgery. J Clin Anesth 34:197-203

23. Rosenberg J, Herring WJ, Blobner M, Mulier JP, Rahe-Meyer N, Woo T, Li MK, Grobara P, Assaid CA, Fennema H Szegedi A (2017) Deep neuromuscular blockade improves laparoscopic surgical conditions: a randomized, controlled study. Adv Ther 34:925-936

24. Barrio J, Errando CL, García-Ramón J, Sellés R, San Miguel G, Gallego J (2017) Influence of depth of neuromuscular blockade on surgical conditions during low-pressure pneumoperitoneum laparoscopic cholecystectomy: a randomized blinded study. J Clin Anesth 42:26-30

25. Serpa Neto A, Hemmes SN, Barbas CS, Beiderlinden M, Biehl M, Binnekade JM, Canet J, Fernandez-Bustamante A, Futier E, Gajic O, Hedenstierna G, Hollmann MW, Jaber S, Kozian A, Licker M, Lin WQ, Maslow AD, Memtsoudis SG, Reis Miranda D, Moine P, $\mathrm{Ng}$ T, Paparella D, Putensen C, Ranieri M, Scavonetto F, Schilling T, Schmid W, Selmo G, Severgnini P, Sprung J, Sundar S, Talmor D, Treschan T, Unzueta C, Weingarten TN, Wolthuis EK, Wrigge H, Gama de Abreu M, Pelosi P, Schultz MJ, PROVE Network Investigators (2015) Protective versus conventional ventilation for surgery: a systematic review and individual patient data metaanalysis. Anesthesiology 123(1):66-78

26. Mulier JP, Dillemans B, Van Cauwenberge S (2010) Impact of the patient's body position on the intraabdominal workspace during laparoscopic surgery. Surg Endosc 24:1398-1402

27. Vlot J, Wijnen R, Stolker RJ, Bax KN (2014) Optimizing working space in laparoscopy: CT measurement of the effect of prestretching of the abdominal wall in a porcine model. Surg Endosc 28:841-846

28. Van Wijk RM, Watts RW, Ledowski T, Trochsler M, Moran JL, Arenas GW (2015) Deep neuromuscular block reduces intraabdominal pressure requirements during laparoscopic cholecystectomy: a prospective observational study. Acta Anaesthesiol Scand 59:434-440

29. Kim MH, Lee KY, Lee KY, Min BS, Yoo YC (2016) Maintaining optimal surgical conditions with low insufflation pressures is possible with deep neuromuscular blockade during laparoscopic colorectal surgery: a prospective, randomized, double-blind, parallel-group clinical trial. Medicine 95:e2920

30. Serpa Neto A, Hemmes SN, Barbas CS, Beiderlinden M, Fernandez-Bustamante A, Futier E, Hollmann MW, Jaber S, Kozian A, Licker M, Lin WQ, Moine P, Scavonetto F, Schilling T, Selmo G, 
Severgnini P, Sprung J, Treschan T, Unzueta C, Weingarten TN, Wolthuis EK, Wrigge H, Gama de Abreu M, Pelosi P, Schultz MJ, PROVE Network investigators (2014) Incidence of mortality and morbidity related to postoperative lung injury in patients who have undergone abdominal or thoracic surgery: a systematic review and meta-analysis. Lancet Respir Med 2(12):1007-1015

31. Cinnella G, Grasso S, Spadaro S, Rauseo M, Mirabella L, Salatto P, De Capraris A, Nappi L, Greco P, Dambrosio M (2013) Effects of recruitment maneuver and positive end-expiratory pressure on respiratory mechanics and transpulmonary pressure during laparoscopic surgery. Anesthesiology 118(1):114-122

32. D’Antini D, Rauseo M, Grasso S, Mirabella L, Camporota L, Cotoia A, Spadaro S, Fersini A, Petta R, Menga R, Sciusco A, Dambrosio M, Cinnella G (2018) Physiological effects of the open lung approach during laparoscopic cholecystectomy: focus on driving pressure. Minerva Anestesiol 84(2):159-167

33. Regli A, De Keulenaer BL, Singh B, Hockings LE, Noffsinger B, van Heerden PV (2017) The respiratory pressure-abdominal volume curve in a porcine model. Intensive Care Med Exp 5:11
34. Cortes-Puentes GA, Gard KE, Adams AB, Faltesek KA, Anderson CP, Dries DJ, Marini JJ (2013) Value and limitations of transpulmonary pressure calculations during intra-abdominal hypertension. Crit Care Med 41(8):1870-1877

35. Mulier JP, Dillemans BRS, Crombach M, Missant C, Sels A (2009) On the abdominal pressure volume relationship. Internet J Anesthesiol 21:1

36. Malbrain ML, Peeters Y, Wise R (2016) The neglected role of abdominal compliance in organ-organ interactions. Crit Care 20(1):67

37. Allaix ME, Furnée EJ, Mistrangelo M, Arezzo A, Morino M (2016 Oct) Conversion of laparoscopic colorectal resection for cancer: what is the impact on short-term outcomes and survival? World J Gastroenterol 22(37):8304-8313

\section{Affiliations}

\section{Oscar Diaz-Cambronero ${ }^{1}$ - Blas Flor Lorente ${ }^{2} \cdot$ Guido Mazzinari $^{3}$. Maria Vila Montañes ${ }^{1} \cdot$ Nuria García Gregorio ${ }^{1}$. Daniel Robles Hernandez ${ }^{4}$. Luis Enrique Olmedilla Arnal ${ }^{5}$. Maria Pilar Argente Navarro ${ }^{1}$. Marcus J. Schultz ${ }^{6,7}$. Carlos L. Errando ${ }^{8}$. for the IPPColLapSe study group}

1 Department of Anesthesiology \& Perioperative Medicine Research Group, Hospital Universitario y Politécnico la Fe. Valencia España, Avinguda de Fernando Abril Martorell 106, 46026 Valencia, Spain

2 Colorectal Surgery, Hospital Universitario y Politecnico la Fe, Valencia, Spain

3 Department of Anesthesiology, Hospital de Manises, Valencia, Spain

4 Department of Anesthesiology, Hospital General Universitario de Castellon, Castellón de la Plana, Spain
5 Department of Anesthesiology, Hospital General Universitario Gregorio Marañon, Madrid, Spain

6 Department of Intensive Care \& Laboratory of Experimental Intensive Care and Anesthesiology (L.E.I.C.A), Academic Medical Center, Amsterdam, The Netherlands

7 Mahidol-Oxford Tropical Medicine Research Unit (MORU), Mahidol University, Bangkok, Thailand

8 Department of Anesthesiology, Consorcio Hospital General Universitario de Valencia, Valencia, Spain 